\title{
Interleukin-8 Concentrations Are Elevated in Bronchoalveolar Lavage, Sputum, and Sera of Children with Cystic Fibrosis
}

\author{
TARANEH P. DEAN, YALEI DAI, JANIS K. SHUTE, MARTIN K. CHURCH, AND \\ JOHN O. WARNER \\ Child Health /T.P.D., Y.D., J.O.W./ and Clinical Pharmacology Group. /Y.D., J.K.S., M.K.C.J. Liniversity of \\ Southampton. Southampton. SO9 $4 X Y$, England
}

\begin{abstract}
Concurrent pulmonary inflammation and neutrophil infiltration are characteristic of children with cystic fibrosis (CF). The production of the major neutrophil chemotactic cytokine IL-8 by alveolar macrophages or other cells could be of great importance in the pathology of acute lung disease, but its role in the persistent lung inflammation characteristic of $C F$ has not been evaluated. In this study, we have measured, by ELISA, the concentration of IL-8 in sputum, bronchoalveolar lavage, and sera specimens obtained from children with CF. For comparison, IL-8 in bronchoalveolar lavage obtained from asthmatic patients and from non-CF children with or without lung infection and in sera from age-matched controls was measured. High levels of IL-8 were measured in sputum (mean $=2952 \mathrm{pM}$ ) and in bronchoalveolar lavage (mean $=6624 \mathrm{pM}$ ) from CF patients. In both cases, there was a significant correlation between clinical status (Schwachman score) and IL-8 levels. This was not true for IL-8 levels measured in sera, which nevertheless were significantly higher in $C F$ patients $(p=0.0001)$ than in normal controls in the over-10-y age group. (Pediatr Res 34: 159161, 1993)
\end{abstract}

\section{Abbreviations}

CF, cystic fibrosis

LPS, lipopolysaccharide

BAL, bronchoalveolar lavage

Chronic pulmonary infection with a number of bacteria, including mucoid Pseudomonas aeruginosa, and the consequent airway inflammation lead to progressive lung damage in CF (1). Although the genetic defect is now known (2) and the gene product identified, its relationship to the susceptibility to chronic suppurative lung disease remains unclear $(3,4)$. The development of an inflammatory response to infection is known to involve a series of cellular events controlled by a variety of polypeptide and lipid mediators. The peptide mediators or cytokines are essential for potentiating an immune response and are distributed by tissue diffusion. Recently, a novel neutrophil chemotactic factor was purified from LPS-stimulated human mononuclear cell-conditioned media and has been named IL-8 $(5,6)$. IL-8 in its mature form consists of 72 amino acids with a molecular mass of $8.3 \mathrm{kD}$. It is the major neutrophil chemoattractant in

Received August 24, 1992; accepted February 11. 1993.

Correspondence: Dr. T. P. Dean. Child Health, Centre Block, Level G. Southampton General Hospital, Southampton, SO9 4XY. Hants. United Kingdom.

Supported by the Cystic Fibrosis Trust. the lung (7) and stimulates the respiratory burst and degranulation of neutrophils, resulting in the release of lysosomal enzymes known to contribute to the lung damage in CF (8-10).

In this study, we have measured IL-8 in the sputum, BAL, and serum of children with CF. Results from serum assays have been compared with age-matched controls to establish whether this measurement provides a marker of inflammation. The levels in the CF children were also assessed in relation to the severity of lung disease to establish whether IL-8 could be implicated in the disease process.

\section{MATERIALS AND METHODS}

Study Group. This study was performed on children with CF attending the CF clinic at Southampton General Hospital, Hants, UK. Diagnosis of CF was established by typical manifestations of the disease and confirmed by sweat iontophoresis (sweat $\mathrm{Na}$ $>70 \mathrm{mmol} / \mathrm{L}$ ). The patients ranged from 4 to $18 \mathrm{y}$ of age with a mean age of $8 \mathrm{y}$. Normal controls were recruited from the pediatric day surgery unit (age range 5-16 y, mean 9 y). Potential control subjects were not enrolled if they had any form of lung disease (asthma, pneumonia, bronchitis, etc.), a history of recent or current bacterial or parasitic infection, use of anti-inflammatory drugs, or any malignancy. This investigation was approved by the University of Southhampton ethical committee. Informed consent was obtained before enrollment and sample collection.

Clinical evaluation of the patients was carried out by Schwachman score (11).

Specimen Processing. Sputum collection. During the clinic, patients were encouraged to expectorate sputum into a sterile tube. One $\mathrm{g}$ of sputum was collected from each patient and added to saline $(1 \mathrm{~mL})$. The mixture was vortexed vigorously for $5 \mathrm{~min}$ and centrifuged at $700 \times g$ for $15 \mathrm{~min}$ at $4^{\circ} \mathrm{C}$. Aliquots of the supernatant were frozen at $-70^{\circ} \mathrm{C}$ until assayed. Samples were diluted when necessary.

$B A L$ (12). Patients were fasted for at least $4 \mathrm{~h}$ before the procedure. Premedication consisted of pethidine $(1-2 \mathrm{mg} / \mathrm{kg})$ and midazolam $(0.1-0.3 \mathrm{mg} / \mathrm{kg})$, both given i.v. Upper-airway anesthesia was obtained with Lignocaine gel (Antigen Pharmaceuticals Ltd., Roscrea, Ireland), and $1 \%$ Lignocaine liquid (instilled through the working channel of the bronchoscope) was used to anesthetize the vocal cords, carina, and both main bronchi. The bronchoscope (Olympus, New Hyde Park, NY: external diameter $3.5 \mathrm{~mm}$, working channel $1 \mathrm{~mm}$ ) was passed through the nose. Repeated small-volume bronchial lavage with $10 \mathrm{~mL}$ of warmed normal saline was done on each occasion with the bronchoscope wedged in a subsegmental bronchus. BAL fluid was filtered through one layer of sterile gauze and centrifuged at $400 \times g$ for $10 \mathrm{~min}$ at $22^{\circ} \mathrm{C}$. Aliquots of BAL supernatant fluid were frozen at $-70^{\circ} \mathrm{C}$ until assayed. This investigation was conducted on children who had a clear clinical need for bron- 
choscopy such as persistent atelectasis or unexplained pulmonary shadows on radiograph.

Serum Collection. Two to three $\mathrm{mL}$ of blood were obtained by venipuncture, placed in a glass tube, and allowed to clot at room temperature for $2 \mathrm{~h}$. After centrifugation at $700 \times g$ for $15 \mathrm{~min}$ at $4^{\circ} \mathrm{C}$, the serum fraction was withdrawn and stored at $-70^{\circ} \mathrm{C}$ for measurement of IL-8. Lavage samples were diluted when necessary.

Assay for $I L-8$. Ninety-six-well microtiter plates (Nunc-Immuno plates, Denmark) were coated with mouse monoclonal anti-human IL-8 $(0.5 \mu \mathrm{g} / 100 \mu \mathrm{L}$, kindly donated by Sandoz Forschungsinstitut, Vienna, Austria) in bicarbonate buffer $(\mathrm{pH}$ 9.6) at $4^{\circ} \mathrm{C}$ overnight. The plates were then washed twice with PBS containing $0.05 \%$ Tween 20 . One hundred $\mathrm{mL}$ of human recombinant IL-8 standard (made up in the PBS containing $2 \%$ human-antibody serum), or a sample was added to each well and the plate was incubated for $2 \mathrm{~h}$ at $37^{\circ} \mathrm{C}$ with shaking, after which the plate was washed twice with wash buffer. At this stage, 100 $\mu \mathrm{L}(0.5 \mu \mathrm{g})$ of goat polyclonal anti-human IL-8 conjugated to alkaline phosphatase was added, and the plate was incubated for an additional $2 \mathrm{~h}$ at $37^{\circ} \mathrm{C}$. The plate was washed three times and substrate, p-nitrophenylphosphate $(10 \mu \mathrm{L})$, was added. The OD was measured at $410 \mathrm{~nm}$. Each assay included two blank buffer wells per plate and an IL-8 standard curve from 2.4 to $1200 \mathrm{pM}$, each concentration in duplicate. Serum samples were assayed undiluted and at 1:2 dilution in duplicate.

Statistics. Statistical analyses were done by Minitab computer program using correlation analysis and Mann-Whitney test.

\section{RESULTS}

IL-8 concentrations in sputum from 26 children with $\mathrm{CF}$ ranged from 74.76 to $11160 \mathrm{pM}$ (mean $=2949.6 \mathrm{pM})$. Unfortunately, we were unable to collect serial samples from these patients because they attended the clinic only once during the course of this study. In addition, because sputum samples cannot be obtained from controls, we were not able to compare these levels with normals. However, when these results were compared with the Schwachman scores of the patients (Fig. 1), there was a significant correlation $(r=-0.94)$ best described by a nonlinear fit.

BAL samples were limited in number because, for ethical reasons, BAL was obtained only when bronchoscopy was carried out for clinical purposes. Five BAL samples were collected, and the IL-8 concentrations in these ranged from 1200 to 11136 $\mathrm{pM}$ (mean $=6618 \mathrm{pM}$ ). There was a significant correlation between IL- 8 concentration in these BAL and the corresponding sputum samples $(r=0.967, p=0.0071)$. The concentration in BAL, like that in sputum, had an inverse relationship with the Schwachman score $(r=-0.92)$.

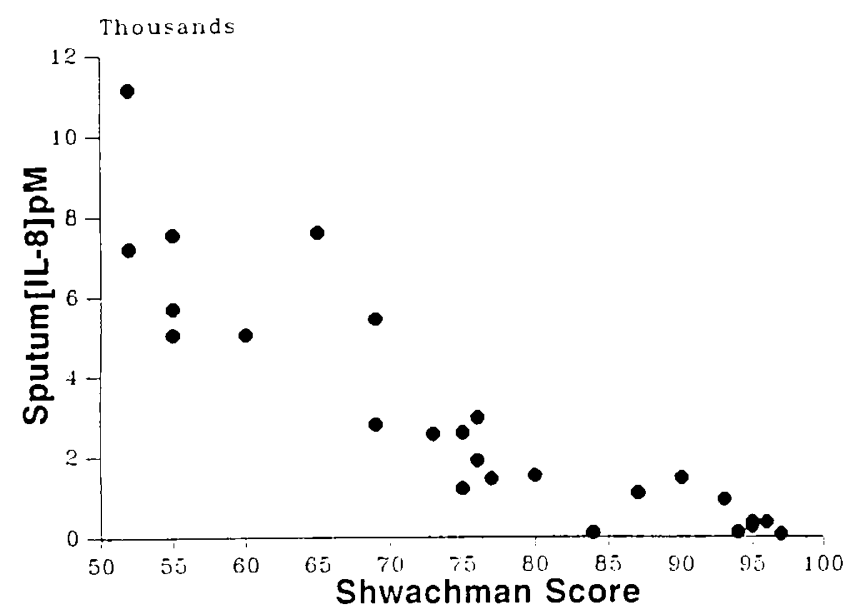

Fig. 1. Correlation between sputum IL-8 concentration and Schwachman score in 26 children with $C F(r=-0.95)$.
In conjunction with this study, we also measured the IL-8 concentration in BAL obtained from eight adult asthmatics and six children with ciliary dyskinesia syndrome whose cultures showed heavy growth of Streptococcus pneumonia and Haemophilus influenzae. IL-8 concentration in asthmatics' BAL ranged from 8.16 to $198 \mathrm{pM}$ (mean $=50.04 \mathrm{pM})$, and in children with infection it ranged from 48 to $984 \mathrm{pM}$ (mean $=302.4 \mathrm{pM})$. BAL IL-8 concentrations were significantly higher in CF patients (mean $6618 \mathrm{pM}$ ) when compared with both these groups.

Serum IL-8 levels were measured in 36 children with CF and 30 controls. As a group, the patients with CF had significantly higher serum concentration of IL-8 $(p=0.0001)$ than normal controls (Fig. 2). The mean IL-8 concentration of patients with $\mathrm{CF}$ was $486.6 \mathrm{pM}$, whereas the controls had a mean value of $61.68 \mathrm{pM}$. Analysis of Schwachman scores and serum IL-8 concentration recorded simultaneously showed no correlation $(r=-0.21)$. In addition, serum IL-8 concentrations were not significantly different in patients with and without Pseudomonas colonization (data not shown).

When comparing serum IL-8 concentrations with corresponding sputum and BAL, no correlation was obtained $(r=0.26$, $p=0.196$ for serum and sputum; $r=0.72, p=0.17$ for serum and BAL).

Analysis of these data in two age groups, $<10 \mathrm{y}$ and $>10 \mathrm{y}$, showed that there was no significant statistical difference between patients and controls $(p=0.08)$ when comparing children less than 10 y of age. However, IL-8 concentrations were significantly higher than controls in those above $10 \mathrm{y}$ of age $(p<0.0001)$. Within both patient and control groups, there was a significant difference between the two age groups. In controls, the IL-8 concentration was significantly lower $(p=0.001)$ in those above $10 \mathrm{y}$ of age compared with the younger age group. The opposite was true in the CF group, with IL-8 concentration significantly higher $(p=0.0137)$ in those above $10 \mathrm{y}$ of age compared with those below. Figure 3 shows the correlation between age and IL8 concentration in serum for both the patients and controls. In both groups, there was a strong correlation with age $(r=+0.522$ and -0.810 for patients and controls, respectively). Our data suggest that, in normal individuals, IL-8 concentration decreases with age, emphasizing the need for age-matched controls, whereas in children with $\mathrm{CF}$, it increases as they grow older and usually have increasing lung disease.

\section{DISCUSSION}

The continuous antigenic stimulation with chronic airway bacterial infection in patients with CF leads to a number of immunologic abnormalities (13-18).

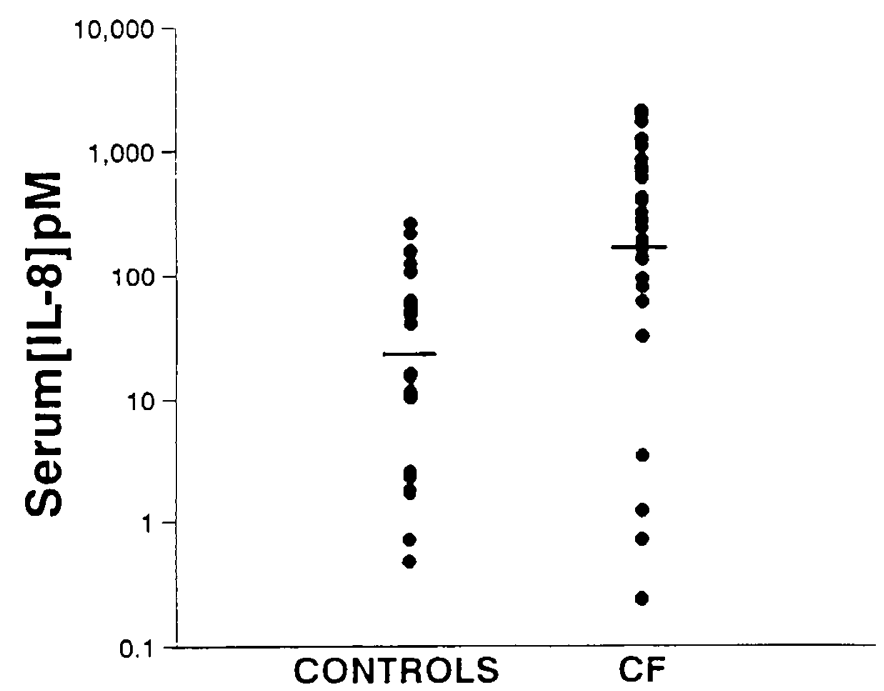

Fig. 2. Comparison of serum IL-8 concentration in 36 children with $\mathrm{CF}$ and 30 controls $(p=0.0001)$. Bars indicate median value. 


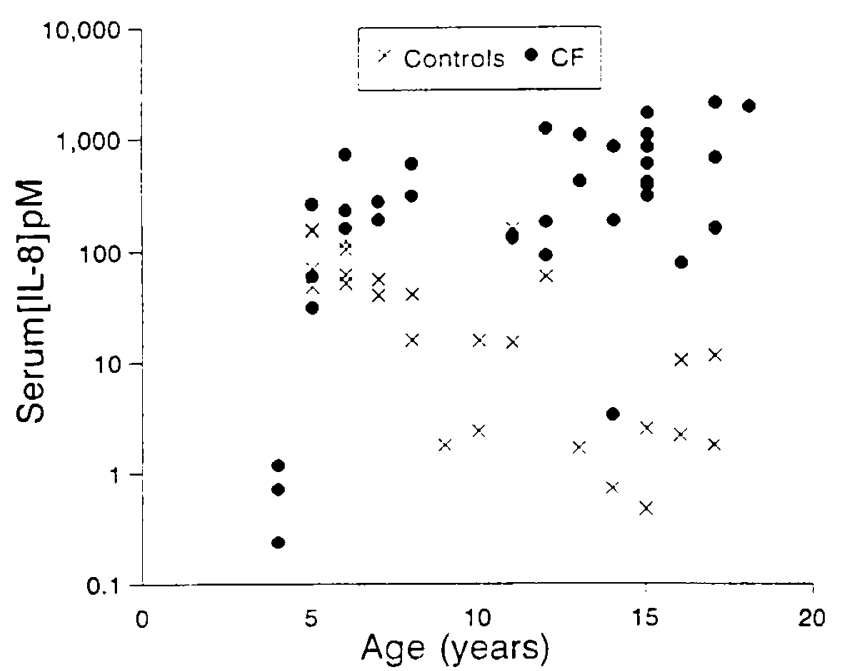

Fig. 3. Correlation between age and serum IL-8 concentration in patients and controls.

Our findings are interesting observations that add to the understanding of physiologic processes in CF. It is clearly demonstrated that IL-8 concentrations are significantly higher in patients with CF. IL-8 has been shown to be produced by many cells, including epithelial cells, fibroblasts, hepatocytes, keratinocytes, endothelial cells, and neutrophils (19-22). There is a great degree of stimulus specificity with regard to IL-8 production from these cell types. Within the lung, alveolar macrophages are the major sources of IL-8 (23), although other cells also produce this cytokine. Upon LPS challenge to the CF lung, the alveolar macrophage responds by synthesizing not only $1 \mathrm{~L}-8$ but also nonchemotactic cytokines, IL-1, and tumor necrosis factor- $\alpha$, which amplify the signal for neutrophil recruitment by inducing the production of IL-8 from type II pneumocytes, lung fibroblasts, and pulmonary endothelial cells (21). The expression of IL-8 leads to neutrophil accumulation and activation, as is seen in the inflammatory processes in the CF lung. We hypothesize that high serum concentrations of circulating IL-8 in CF patients represent either a spillover from a localized inflammatory response in the lung or wider systemic activation of cells of the monocyte-macrophage group in response to LPS and to antigen and antibody complexes (24). Our results showed no correlation between the clinical scores of the patients and the serum IL-8 concentrations. However, the ELISA used measures free, active IL-8, and because IL-8 binds not only to neutrophils, T cells, and red blood cells (25), but also to an IgG autoantibody (26), the free, effective serum concentrations of IL-8 may not reflect that of whole blood and therefore the clinical state of the patients. Nevertheless, younger children, normally with less lung disease, had levels not significantly different from controls. However, we found that the IL-8 concentration of the lung fluids correlated well with the clinical scores, which is indicative of an association with degree of airway inflammation. Because sputum and BAL IL-8 concentrations correlated extremely well, this may enable us to use sputum rather than BAL samples to evaluate IL-8 concentrations and consequently the inflammatory state of the lung.

The cross-sectional observations are interesting and indicate that in the CF group the IL- 8 concentration increases with age, whereas in the controls, it decreases. This can well be expected, because in the CF children the disease manifests itself more severely as they grow. In controls, it is likely that the younger children are experiencing more intercurrent viral infections than are older children.
Our observations clearly indicate the presence of IL-8 in the inflammatory processes of $\mathrm{CF}$. It may provide a clinically useful marker for monitoring progress of the lung disease.

Acknowledgment. The authors thank Sandoz Forschungsinstitut for providing the antibodies for ELISA assays.

\section{REFERENCES}

1. Wood RE, Boat TF, Doershuk CF 1976 Cystic fibrosis. Am Rev Respir Dis 113:833-878

2. Kerem BS, Rommens JM, Buchana JA, Markiewicz D. Cox TK. Chakravati A. Buchwald M. Tsui LC 1989 Identification of the cystic fibrosis gene: genetic analysis. Science 245:1073-1079

3. Doring G. Albus A. Hoiby N 1988 Immunological aspects of cystic fibrosis. Chest 4(suppl):119-115

4. McFarlane $\mathrm{H} 1986$ Humoral mediated immunity in cystic fibrosis. In: Shapira E, Wilson GB (eds) Immunological Aspects of Cystic Fibrosis. CRC Press. Boca Raton, FL. pp 79-100

5. Yoshimura T, Matsushima K, Oppenheim JJ, Leonard EJ 1987 Neutrophil chemotactic factor produced by lipopolysaccharide (LPS)-stimulated human blood mononuclear leucocytes: partial characterization and separation from interleukin I (IL I). J Immunol 139:788-793

6. Matsushima K, Morishita K. Yoshimura T. Lavu S, Kobayashi Y, Lee W, Appella E, Kung HF, Leonard EJ, Oppenheim JJ 1988 Molecular cloning of a human monocyte-derived neutrophil chemotactic factor. J Exp Med 167:1883-1893

7. Kunkel SL. Standiford T. Kasahara K. Strieter M 1991 Interleukin-8 (IL-8): the major neutrophil chemotactic factor in the lung. Exp Lung Res 17: $17-23$

8. Colditz 1. Zwahlen R. Dewald B. Baggiolini M 1989 In vivo inflammatory activity of neutrophil-activating factor, a novel chemotactic peptide derived from human monocytes. Am J Pathol 134:755-760

9. Colditz IG. Zwahlen RD. Baggiolini M 1990 Neutrophil accumulation and plasma leakage induced in vivo by neutrophil-activating peptide-1. J Leukocyte Biol 48:129-137

10. McElvaney NG. Hubbard RC. Birrer P 1991 Aerosol XI-antitrypsin treatment for cystic fibrosis. Lancet 337:392-394

11. Schwachman H. Kulczycki LL 1958 Long term study of one hundred and five patients with cystic fibrosis. Am J Dis Child 96:6-15

12. Raine J, Warner JO 1991 Fiberoptic bronchoscopy without general anesthetic. Arch Dis Child 66:481-484

13. Dagli E, Warner JA. Besley CR. Warner JO 1992 Raised serum soluble interleukin-2 receptor concentration in cystic fibrosis patients with and without evidence of lung disease. Arch Dis Child 67:479-481

14. Suter S. Schaad UB. Roux L. Nydegger UE. Waldvogel FA 1984 Granulocyte neutral proteases and Pseudomonas elastase as possible causes of airway damage in patients with cystic fibrosis. J Infect Dis 3:523-531

15. Knutsen AP. Mueller KR $1990 \mathrm{~T}$ cell cytotoxicity in cystic fibrosis: relationship to pulmonary status. Int Arch Allergy Appl Immunol 93:54-58

16. Noyes BE, Banas RA. Paradis IL. Dauber JH 1992 Accessory cell function of blood monocytes in cystic fibrosis. Am Rev Resp Dis 145:A119(abstr)

17. Thomassen MJ. Demko CA. Doershuk CF 1987 Cystic fibrosis: a review of pulmonary infections and interventions. Pediatr Pulmonol 3:334-351

18. Meyer KC. Lewandoski JR. Zimmerman JJ. Nunley D. Calhoun WJ. Dopico GA 1991 Human neutrophil elastase and elastase/alpha ${ }_{1}$-antiprotease complex in cystic fibrosis. Am Rev Respir Dis 144:580-585

19. Rolfe MW. Kunkel SL, Standiford TJ, Chensue SW, Allen RM, Evanoff HL, Phan SH. Strieter RM 1991 Pulmonary fibroblast expression of interleukin8: a model for alveolar macrophage-derived cytokine networking. Am J Respir Cell Mol Biol 5:493-501

20. Thornton AJ. Strieter RM, Lindley IM. Baggiolini M. Kunkel SL 1990 Cytokine-induced expression of a neutrophil chemotactic factor/IL-8 in human hepatocytes. J Immunol 2:2609-2613

21. Nakamura H. Yoshimura K. Ari Jaffe H. Crystal RG 1991 Interleukin-8 gene expression in human bronchial epithelial cells. J Biol Chem 266:1961119617

22. Bazzoni F. Cassatella MA, Rossi F, Ceska M, Dewald B. Baggiolini M 1991 Phagocytosing neutrophils produce and release high amounts of the neutrophil-activating peptide 1/interleukin 8. J Exp Med 173:771-774

23. Strieter RM. Chensue SW, Basha MA, Standiford TJ, Lynch JP, Baggiolini M. Kunkel SL 1990 Human alveolar macrophage gene expression of interleukin8 by tumor necrosis factor-alpha. lipopolysaccharide, and interleukin-1 beta. Am J Respir Cell Mol Biol 2:3221-3226

24. Hoiby N. Doring G. Schiotz PO 1986 The role of immune complexes in the pathogenesis of bacterial infections. Ann Rev Microbiol 40:29-53

25. Darbonne WC, Rice GC, Mohler MA. Apple T, Hebert CA. Valente AJ, Baker JB 1991 Red blood cells are a sink for interleukin 8, a leucocyte chemotoxin. J Clin Invest 88:1362-1369

26. Peichl P. Ceska M. Broell H. Effenberger F. Lindley IJD 1992 Human neutrophil activating peptide/interleukin 8 acts as an autoantigen in rheumatoid arthritis. Ann Rheumatic Dis 51:19-22 